\title{
The effect of thermal annealing on the properties of alumina films prepared by metal organic chemical vapour deposition at atmospheric pressure
}

\author{
V.A.C. Haanappel, H.D. van Corbach, T. Fransen* and P.J. Gellings \\ University of Twente, Department of Chemical Technology, P. O. Box 217, 7500 AE Enschede (Netherlands) \\ (Received October 8, 1993; accepted in final form November 17, 1993)
}

\begin{abstract}
Thin films deposited at $330^{\circ} \mathrm{C}$ by metal organic chemical vapour deposition on stainless steel, type AISI 304, were annealed in a nitrogen atmosphere for 1,2 and $4 \mathrm{~h}$ at 600,700 and $800^{\circ} \mathrm{C}$. The film properties, including the protection of the underlying substrate against high temperature corrosion, the chemical composition of the film and the microstructure, were investigated.

Corrosion experiments performed at $450^{\circ} \mathrm{C}$ in a hydrogen sulphide containing gas, showed that the cracks in the alumina films almost completely disappeared after a post-deposition heat treatment, probably as a result of stress relaxation. The porosity of the alumina films was not affected by this heat treatment. X-ray diffraction measurements of these films, deposited at $330^{\circ} \mathrm{C}$, revealed an amorphous structure. Owing to the thermal annealing process, the amorphous alumina films were converted to $\gamma$-alumina, and OH-groups disappeared.
\end{abstract}

\section{Introduction}

The deposition of thin alumina films by metal organic chemical vapour deposition (MOCVD) is increasingly applied [1-13]. Applications of alumina films are found in the field of semiconductor device applications as intermetal dielectrics for silicon integrated circuits, as solar selective coatings and protective coatings for solar cells [2-4]. At present, silica is used extensively in semiconductor devices [5]. However, silica layers have a high permeability to alkali ions, e.g. sodium, which can easily reach the underlying substrate resulting in device instability [6]. In order to overcome these problems, these silica layers can be replaced by, for example, alumina films which have a very low permeability to alkali ions and other impurities [7,8]. Alumina films can also be used as protective coatings in the field of high temperature corrosion [9]. This study is focused on the formation and characterisation of thin alumina films which can probably replace silica films to improve the corrosion protection.

Several methods have been reported for the preparation of alumina films, such as plasma enhanced MOCVD[10], low pressure MOCVD [11], nonreactive r.f. magnetron sputtering [12] and atmospheric pressure MO CVD (this paper). The choice for the formation of alumina films by MOCVD by means of

*Author to whom correspondence should be addressed. aluminium-tri-sec-butoxide (ATSB) is based upon the low temperature needed. MOCVD is a process of pyrolytic decomposition of a metal alkoxide, also called a "precursor", to produce a non-volatile solid that deposits on a suitably placed substrate [13]. This method has the ability to produce films with desirable properties. Other advantages include the relatively low cost of the equipment and low operating expenses [13].

The aim of this study was to investigate the effect of thermal annealing on some properties of alumina films deposited by MOCVD. The alumina films were deposited by the thermal decomposition of ATSB in a nitrogen atmosphere under atmospheric pressure. Properties such as protection against high temperature corrosion of steels, structure and chemical composition were investigated as a function of the annealing period and the annealing temperature.

\section{Experimental details}

Alumina films were deposited by means of atmospheric pressure MOCVD using ATSB (Janssen Chimica) and dried nitrogen gas. The substrate used in the experiments was a stainless steel, type AISI 304, which was cut from an electropolished metal sheet and ultrasonically cleaned in hexane and ethanol.

A schematic diagram of the experimental set-up was shown in a previous paper [14]. The ATSB is introduced 
in the furnace by passing nitrogen gas through the ATSB bubbler with an equilibrium vapour pressure of ATSB of $0.13 \mathrm{kPa}(1.0 \mathrm{~mm} \mathrm{Hg})$ at $138^{\circ} \mathrm{C}$. The ATSB flow rate was adjusted by controlling the flux of nitrogen gas through the ATSB bubbler at atmospheric pressure. This gas mixture was added to the main nitrogen flow before entering the reaction chamber. The flow rates were controlled by mass flow controllers (type Brooks $5850 \mathrm{TR})$. The deposition reaction was carried out in a quartz tube with a diameter of $45 \mathrm{~mm}$. The uniform temperature zone in the reactor was $120 \mathrm{~mm}$. The specimens were attached, parallel to the gas flow, to a ceramic tube with a thermocouple inside in order to measure the substrate temperature and control the furnace temperature (standard conditions were: substrate temperature, $330^{\circ} \mathrm{C}$; ATSB temperature, $138^{\circ} \mathrm{C}$; flow rate, $6.51 \mathrm{~min}^{-1}$ (STP)). The deposition rate of the films on the metallic substrate was determined by weighing the samples before and after the deposition. In the experiments specimens were used with alumina films of $0.20 \pm 0.05 \mathrm{mg} \mathrm{cm}^{-2}$.

After the deposition process, the samples were exposed to a nitrogen atmosphere with temperatures ranging from 600 to $800^{\circ} \mathrm{C}$, during 1,2 and $4 \mathrm{~h}$ periods without removing them from the furnace. Following the deposition process the furnace was heated to the desired annealing temperature in $20 \mathrm{~min}$. After completion of the thermal annealing period, the temperature was decreased to below $300^{\circ} \mathrm{C}$ before the samples were removed from the furnace.

Corrosion experiments were performed in order to investigate the protective capacity, i.e. the porosity, of the films against aggressive gas components, such as oxygen and sulphur, at high temperatures and were carried out in a closed system for $24 \mathrm{~h}$. The system was first flushed with argon for $20 \mathrm{~h}$ with a flow rate of $16 \mathrm{l}$ $\mathrm{h}^{-1}$. The argon was saturated with water at $15^{\circ} \mathrm{C}$. A mixture of $5 \% \mathrm{H}_{2} \mathrm{~S}$ in $\mathrm{H}_{2}$ with a flow rate of $4 \mathrm{lh}^{-1}$ was then introduced into the argon flow. After $2 \mathrm{~h}$, the furnace was heated to the test temperature $\left(\right.$ i.e. $450^{\circ} \mathrm{C}$ ) to stabilize the flow. The whole system was flushed for another $2 \mathrm{~h}$ and then closed. It had previously been found that no relevant difference in corrosion rate and corrosion products was obtained between a closed system and a system with a continuous flow, if the reactive gas consumption did not exceed $20 \%$.

The morphology and the composition of the corroded specimens were investigated by means of optical and scanning electron microscopes (JEOL-35 CF), the latter equipped with an energy dispersive $\mathrm{X}$-ray analysis (EDX) system (Kevex Delta, class III).

To characterize the chemical composition and the depth profile, the alumina films were analysed using a Perkin-Elmer PHI 600 scanning Auger multiprobe. Alternate sputtering and Auger analysis were used for in-depth analysis. The functional groups within the films were measured by Fourier transform infrared spectroscopy (FTIR), using a Nicolet 20 SX FTIR apparatus. Owing to the non-transparency of the specimens, the spectrometer was equipped with a diffuse reflection cell [9]. The microstructure of the films was investigated by X-ray diffraction (XRD), using a Philips PW 1710 X-ray diffractometer with monochromatic $\mathrm{Cu} K \alpha$ radiation and a high resolution transmission electron microscope, model JEOL $200 \mathrm{CX}$.

\section{Results}

The kinetic aspects of the deposition of the alumina films on AISI 304 by the MOCVD process have been discussed extensively in a previous paper [14]. The experimental activation energy for the heterogeneous reaction was found to be $83 \pm 5 \mathrm{~kJ} \mathrm{~mol}^{-1}$.

The effect of temperature and exposure time of the thermal treatment process on the corrosion attack is shown in Fig. 1. The relative weight gain is the ratio between the weight gain of a coated and an uncoated sample after the corrosion experiments. From these figures it is clear that the amount of corrosion product (relative weight gain) was not extensively reduced by the post-deposition annealing. At times even an increase in the relative weight gain was measured. Scanning electron microscopy (SEM) examinations showed that corrosion products (Fe-rich sulphides) were formed on the outer surface of the alumina film.

In general, the surface of the specimens showed an extensive reduction of the number of cracks owing to heat treatment. In some cases no cracks were found. Corrosion products were locally formed on the surface, probably because of the presence of porosity in the film. For samples with and without a post-deposition thermal treatment, it was observed that after higher deposition temperatures fewer corrosion products were found on the specimens (Fig. 2).

The composition and the depth profile of the annealed alumina films were investigated by Auger electron spectroscopy (AES) in combination with ion sputtering. From the steady state Auger spectra (see survey scan in Fig. 3), it is clear that next to aluminium and oxygen a small amount of carbon was also detected, even after annealing for $4 \mathrm{~h}$ at $800^{\circ} \mathrm{C}$. After one or more sputtering cycles (one cycle corresponds to $1 \mathrm{~min}$ sputtering at a rate of $44 \mathrm{~nm} \mathrm{~min}{ }^{-1}$ ) carbon was no longer found. Figure 4(a) shows the AES depth profile of the alumina film (thickness, $0.55 \mu \mathrm{m}$ ) deposited at $330^{\circ} \mathrm{C}$ (without thermal treatment). The AES depth profiles of the $1 \mathrm{~h}$ at $600{ }^{\circ} \mathrm{C}(0.7 \mu \mathrm{m})$ and the $4 \mathrm{~h}$ at $800^{\circ} \mathrm{C}(0.5 \mu \mathrm{m})$ treated specimens are shown in Figs. 4(b) and 4(c) respectively. From these observations it was found that the alumina-alloy interface was rather sharp for the 
Annealing Temperature $600^{\circ} \mathrm{C}$

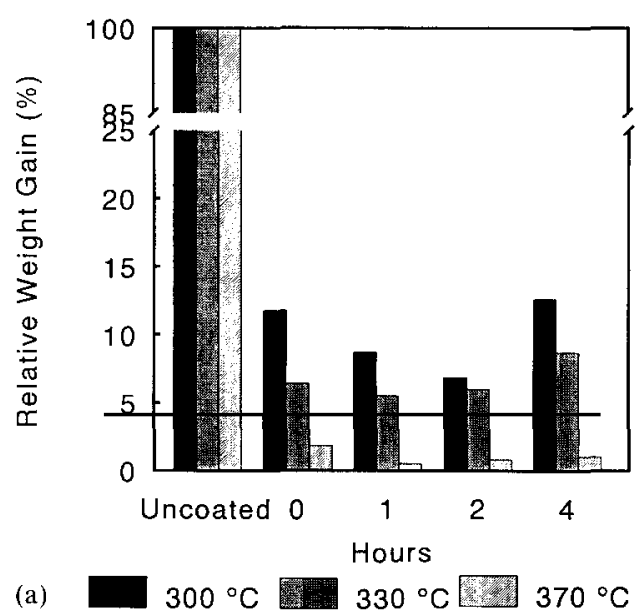

Annealing Temperature $800^{\circ} \mathrm{C}$

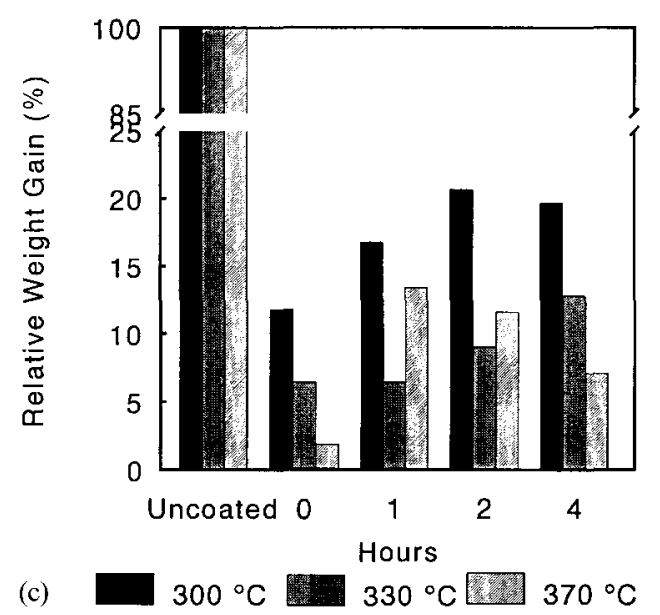

Annealing Temperature $700^{\circ} \mathrm{C}$

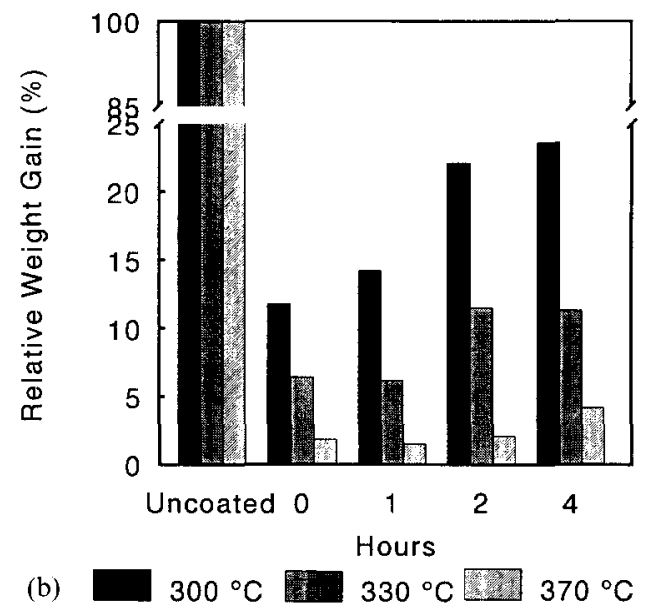

Fig. 1. Bar diagram of the relative weight gain $(\%)$ of the specimens as a function of the thermal annealing time and temperature: annealing temperature (a) $600^{\circ} \mathrm{C}$; (b) $700^{\circ} \mathrm{C}$ and (c) $800^{\circ} \mathrm{C}$.

untreated samples or samples treated at low annealing temperatures and short annealing time. After longer time periods and/or higher annealing temperatures, the interface was no longer very sharp. From Fig. 4(c) it is clear that a certain amount of chromium penetrated into the alumina film. The iron and nickel depth profile did not change after the thermal treatment, even after $4 \mathrm{~h}$ at $800^{\circ} \mathrm{C}$.

The chemical composition of the alumina films obtained in the process described was also analysed by means of X-ray photoelectron spectroscopy (XPS).

To identify functional groups in the alumina film, such as OH-groups which cannot be detected by EDX or AES, FTIR was applied. The FTIR absorbance spectra of the films annealed at $700^{\circ} \mathrm{C}$ are shown in Fig. 5. Two specific absorption bands were found at $900-950 \mathrm{~cm}^{-1}$ and $3000-3700 \mathrm{~cm}^{-1}$, indicative of the $\mathrm{Al}-\mathrm{O}$ and $\mathrm{O}-\mathrm{H}$ bonds respectively $[9,15]$. This figure shows that the $\mathrm{O}-\mathrm{H}$ absorption band decreases in intensity at a given annealing temperature with increasing annealing time. The absorption band around $900-950 \mathrm{~cm}^{-1}$, characteristic for the $\mathrm{Al}-\mathrm{O}$ band, increases in intensity. No pronounced difference was observed regarding the maximum of the $\mathrm{Al}-\mathrm{O}$ peak owing to the different thermal treatment procedures. The maximum of the $\mathrm{Al}-\mathrm{O}$ peak of an unannealed sample lies around $910 \mathrm{~cm}^{-1}$ and shifts to around $928 \mathrm{~cm}^{-1}$ after annealing.

The microstructure of the alumina films was investi- 


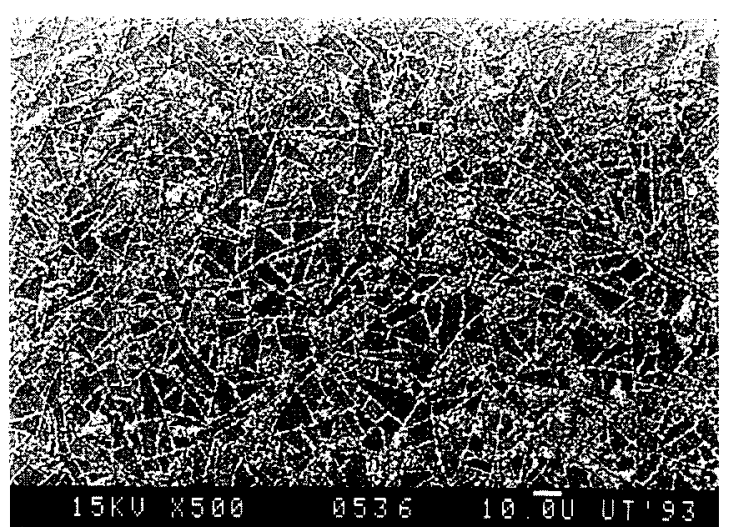

(a)

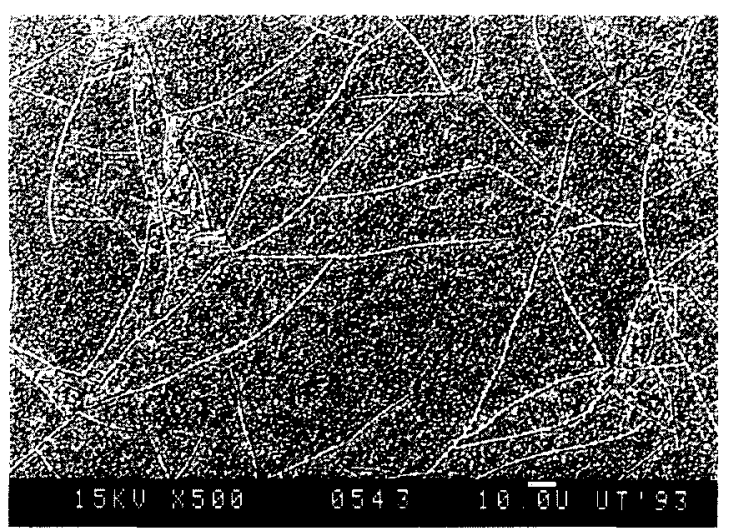

(c)

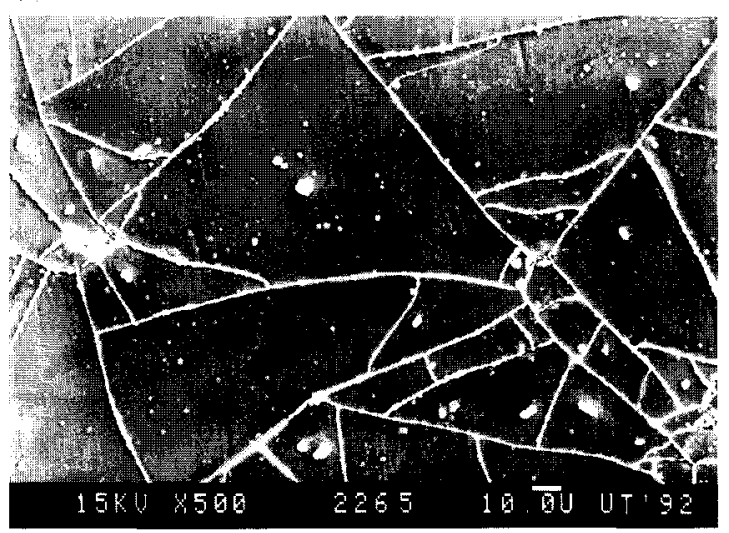

(e)

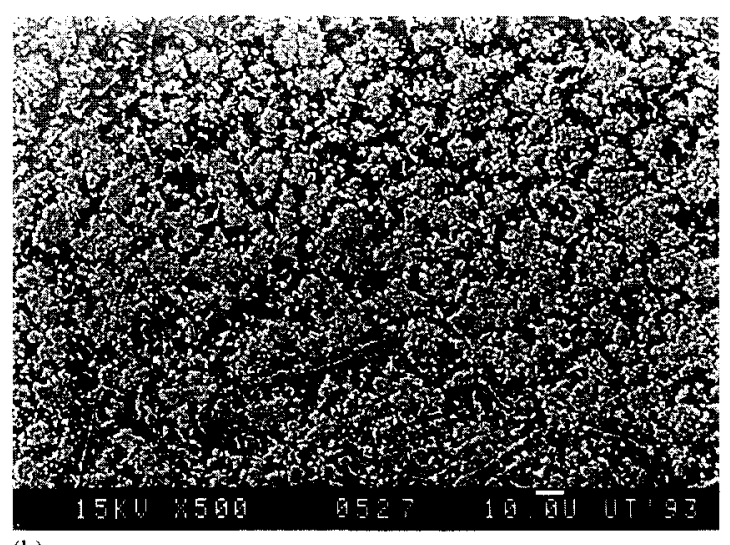

(b)

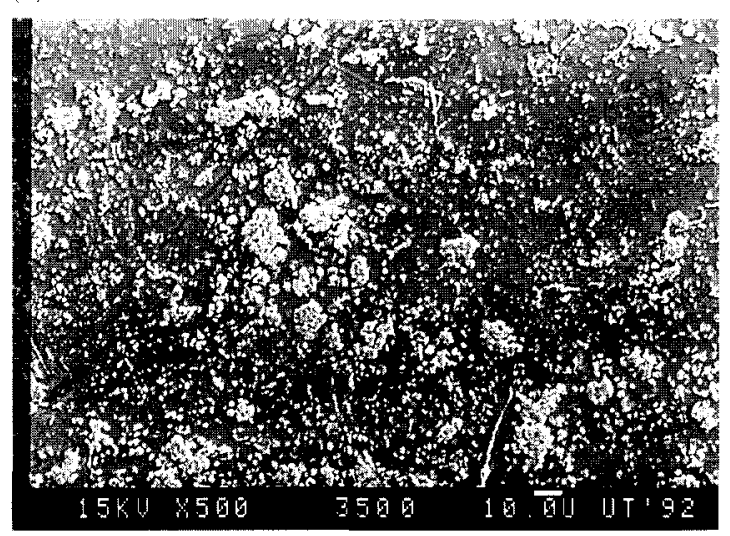

(d)

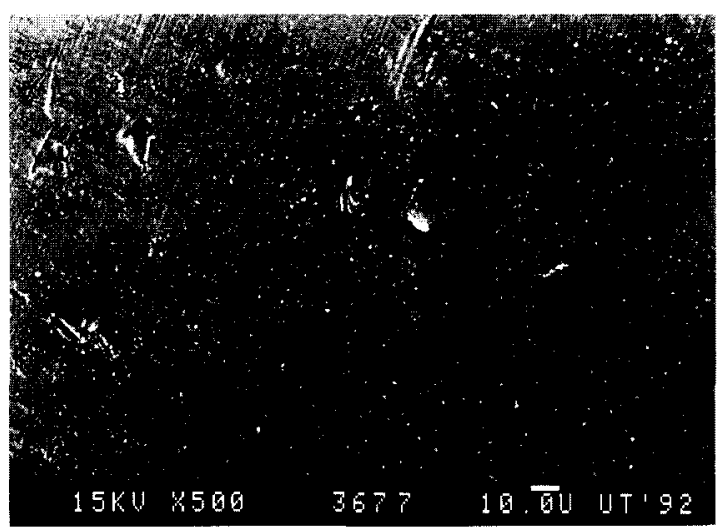

(f)

Fig. 2. SEM image of the surface morphology of the specimens after $24 \mathrm{~h}$ of sulphidation at $450 \mathrm{C}$. Deposition temperature, $300^{\circ} \mathrm{C}$ : (a) unannealed); (b) annealed for $2 \mathrm{~h}$ at $600^{\circ} \mathrm{C}$. Deposition temperature, $330^{\circ} \mathrm{C}$ : (c) unannealed; (d) annealed for $2 \mathrm{~h}$ at $700^{\circ} \mathrm{C}$. Deposition temperature, $370^{\circ} \mathrm{C}$ : (e) unannealed; (f) annealed for $2 \mathrm{~h}$ at $800^{\circ} \mathrm{C}$

gated by XRD. It was previously found [15] that alumina films deposited at various deposition temperatures and analysed by XRD show an amorphous structure. The XRD peaks of the alumina films annealed at $700{ }^{\circ} \mathrm{C}$ for 1,2 and $4 \mathrm{~h}$, and of one sample without any heat treatment, are shown in Fig. 6. On the unannealed specimens only the characteristic XRD peaks of the underlying substrate, AISI 304, could be found:
$2 \theta ;=43.7^{\circ}, 50.9^{\circ}$ and $74.7^{\circ}$. After the post-deposition thermal treatment a small peak was found at $2 \theta ;=44.6^{\circ}$, indicative of the presence of $\gamma$-alumina. This small peak was found for all heat-treated samples.

Additional deposition experiments were performed on polished AISI 304 specimens. It was observed that only at the annealing temperature of $700^{\circ} \mathrm{C}$ for 2 and $4 \mathrm{~h}$, and at $800^{\circ} \mathrm{C}$ for 1,2 and $4 \mathrm{~h}$ did the alumina films 


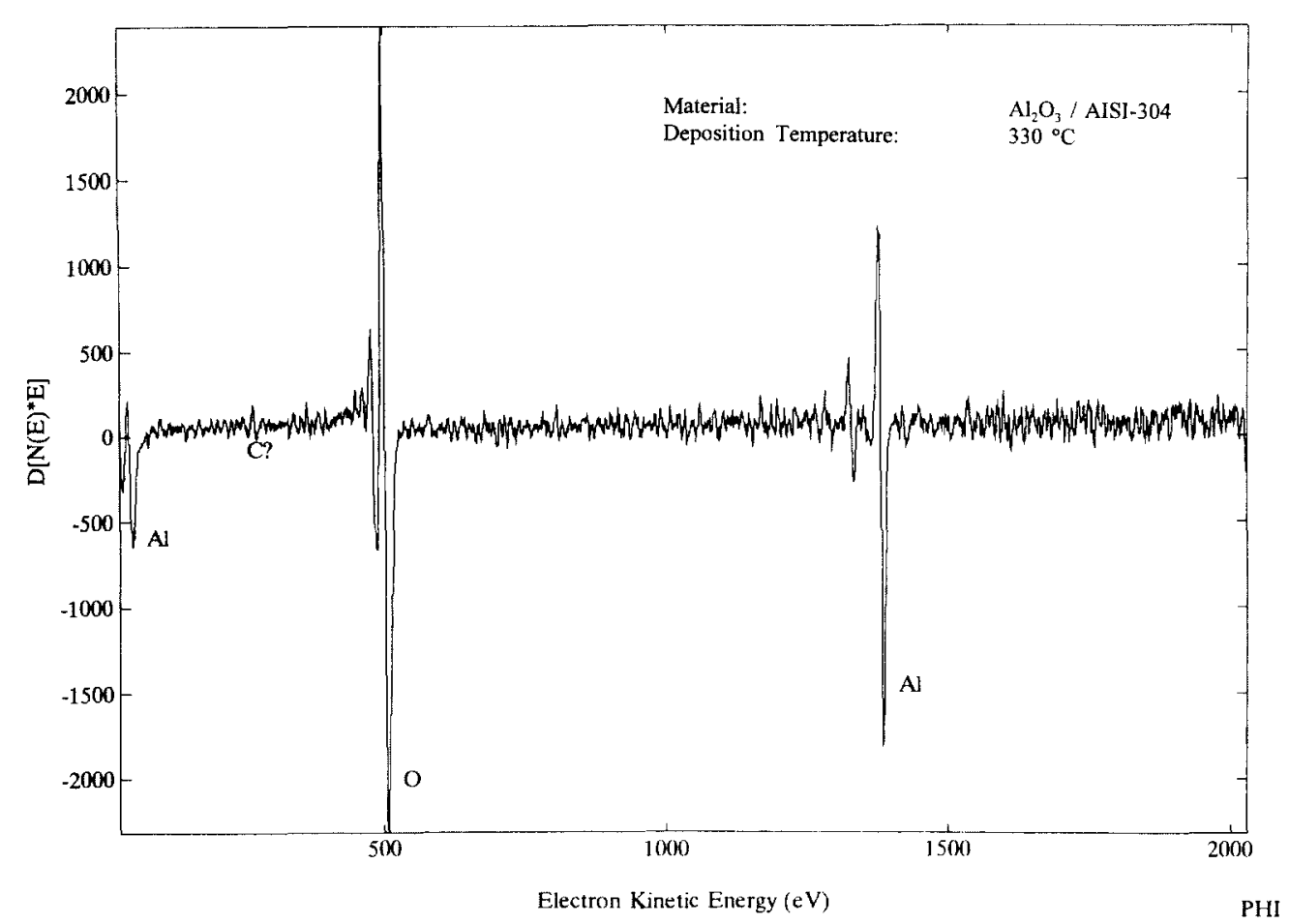

Fig. 3. AES survey scan analysis of the alumina film on AISI 304 , deposited at $330^{\circ} \mathrm{C}$ (unannealed).

crack and delaminate during the cooling period. From examinations with SEM it was found that delamination took place interfacially. Previously, it was found that cracking and delamination of the alumina film occurred after passing a critical thickness of the film during the MOCVD process [16], owing to internal tensile stresses at the outer side of the film. The films bend concavely, as shown in Fig. 7(a).

The alumina films, which crack and delaminate from the underlying substrate after the thermal annealing procedure, bend convexly (see Fig. 7(b)) as a result of the internal compressive stresses concentrated at the outer part of the alumina film. Cracking and delamination of the films after cooling did not occur when substrates were used from the electropolished metal sheet, which might be explained by the higher roughness of the underlying substrate giving larger adhesive forces.

\section{Discussion}

From the weight gain measurements it is clear that the different post-deposition annealing procedures did not result in any significant improvement of the protectiveness of the alumina films against high temperature corrosion of steels. On the outer surface of the specimens, corrosion products were formed after exposure for $24 \mathrm{~h}$ in a hydrogen sulphide containing gas atmosphere, owing to a certain porosity of the alumina films and the existence of cracks in the films.

It was found earlier [15] that the porosity of the alumina film depends significantly on the deposition temperature. Figures 2(a), (c) and (e) show the amount of corrosion products that reduce with increasing deposition temperature. This corresponds well with the results by Boldyrev et al. [17] who found that an increase of the deposition temperature promotes thermal compaction resulting in a denser film structure. The mobility of adsorbed atoms is low - probably as a result of the low deposition temperature. This means that those atoms are not able to move from their adsorption sites to energetically more favourable sites. The existence of pores in the alumina films might also be explained by an incomplete conversion of the ATSB molecules, especially at lower deposition temperatures, as already discussed elsewhere [15]. Also the water vapour released by the dehydration of boehmite $(\mathrm{AlO}(\mathrm{OH}))$ during the deposition may affect the porosity of the alumina film. From previously discussed results $[9,15]$ it is assumed that, owing to the presence of OH-groups, the as-deposited alumina film consists partly of boehmite. According to Stumpf et al. [18], $\gamma$-alumina was found as the crystalline phase after thermal annealing. If $\mathrm{AlO}(\mathrm{OH})$ were incorporated in the film, it would decompose to alumina and water at high temperatures:

$2 \mathrm{AlO}(\mathrm{OH}) \stackrel{\Delta T}{\longrightarrow} \mathrm{Al}_{2} \mathrm{O}_{3}(1-x) \mathrm{H}_{2} \mathrm{O}+\mathrm{xH}_{2} \mathrm{O}$ 
The transition of $\mathrm{AlO}(\mathrm{OH})$ to $\gamma$-alumina was also found by Goton [19], Bugosh et al. [20] and Saalfeld [21]. Goton [19] found dehydroxylation of boehmite into $\mathrm{Al}_{2} \mathrm{O}_{3}$ (with $0.1 \mathrm{~mol} \mathrm{H}_{2} \mathrm{O}$ per mole of $\mathrm{Al}_{2} \mathrm{O}_{3}$ ). Bugosh et al. [20] and Saalfeld [21] found that heating of $\mathrm{AlO}(\mathrm{OH})$ results subsequently into $\gamma-\theta$ - and $\alpha$ alumina.

In contrast to the deposition temperature, the postdeposition thermal treatment did not influence the porous structure of the alumina film. This might be explained by the short period (up to $4 \mathrm{~h}$ ) at temperatures up to $800^{\circ} \mathrm{C}$ of the thermal annealing process being too slow to compact the alumina film. Higher temperatures and longer periods may have more effect on the porosity of the alumina films.

Summarizing, it is clear that only the deposition temperature significantly influences the porosity; this is in contrast to the post-deposition heat treatment.

However, the crack density was reduced significantly after the thermal treatment process. These cracks in the
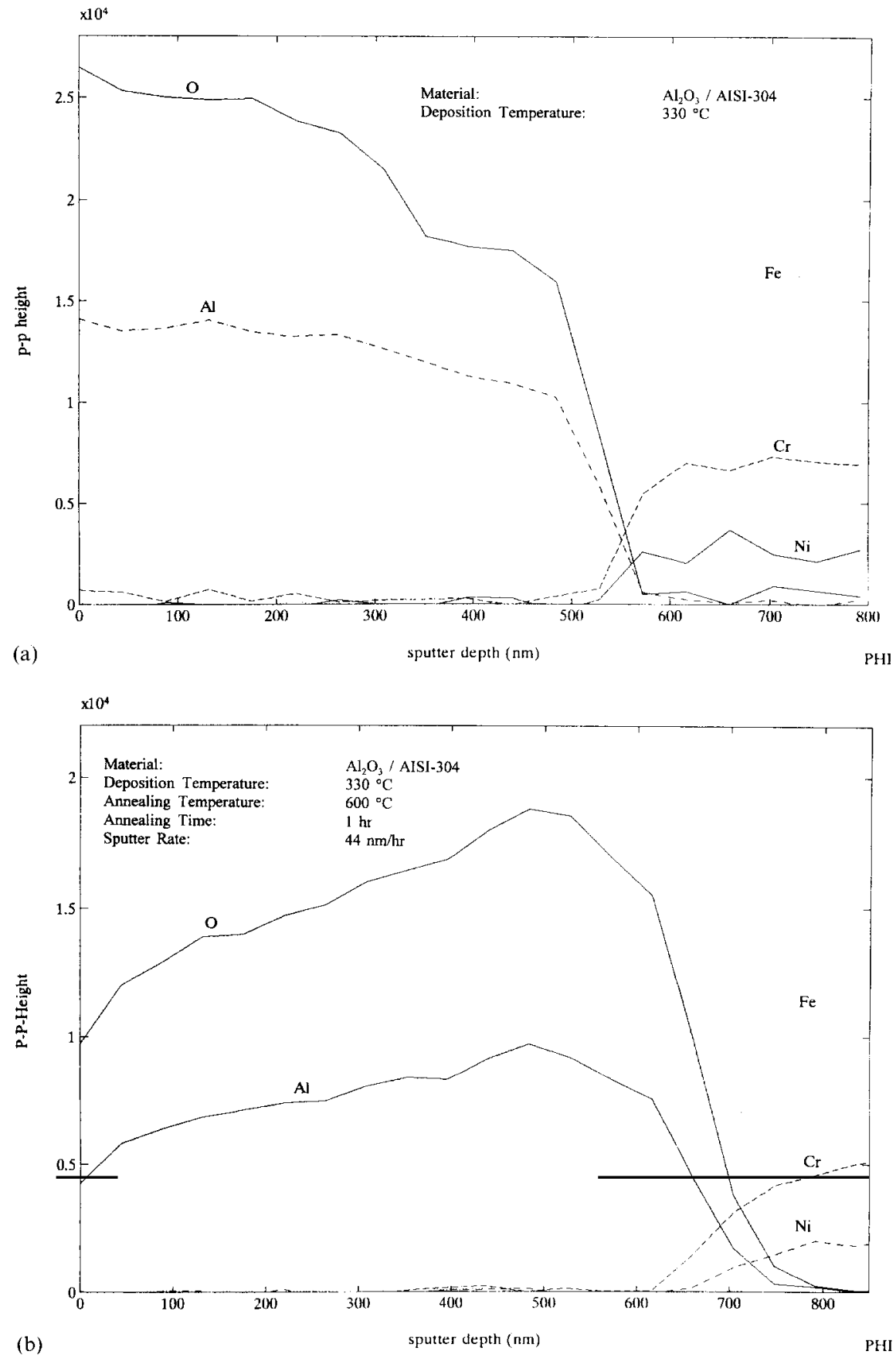


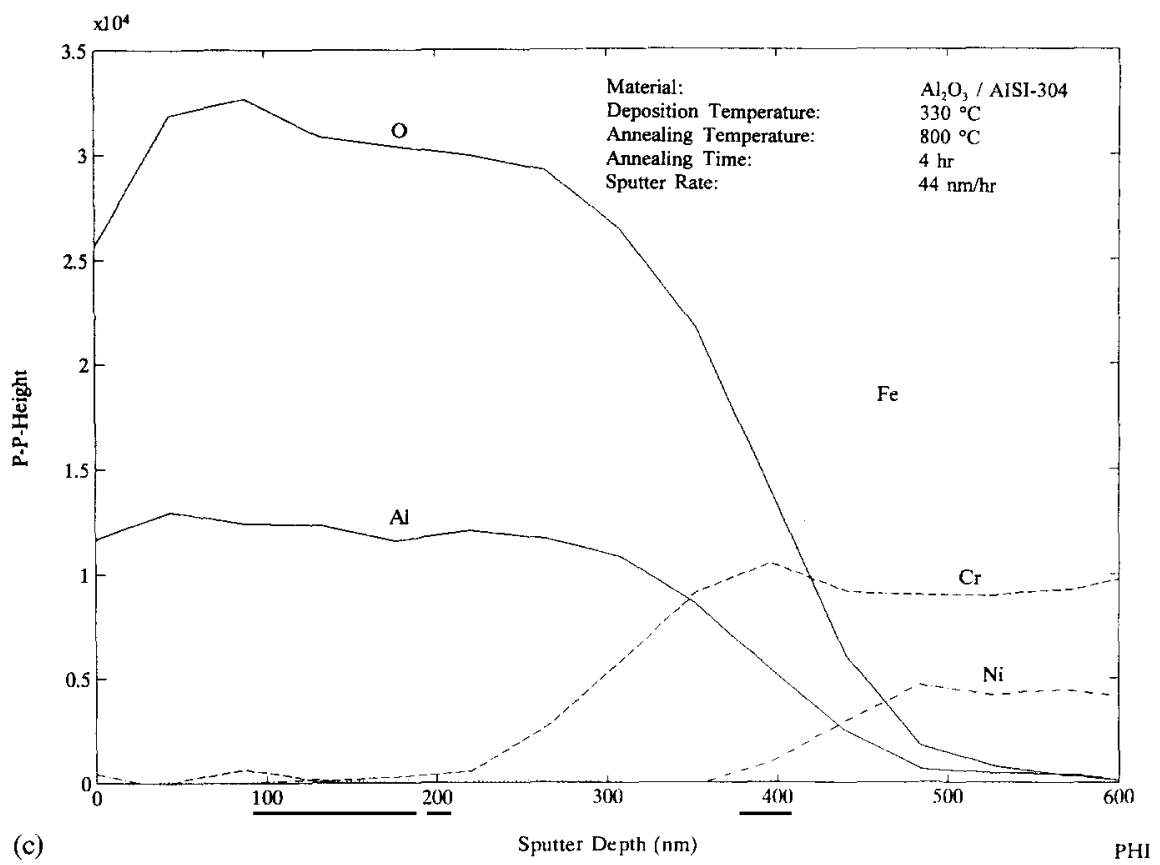

Fig. 4. AES depth profile analysis of the alumina film on AISI 304, deposited at $330^{\circ} \mathrm{C}$ : (a) unannealed; (b) annealed for $1 \mathrm{~h}$ at $600^{\circ} \mathrm{C}$; (c) annealed for $4 \mathrm{~h}$ at $800^{\circ} \mathrm{C}$.

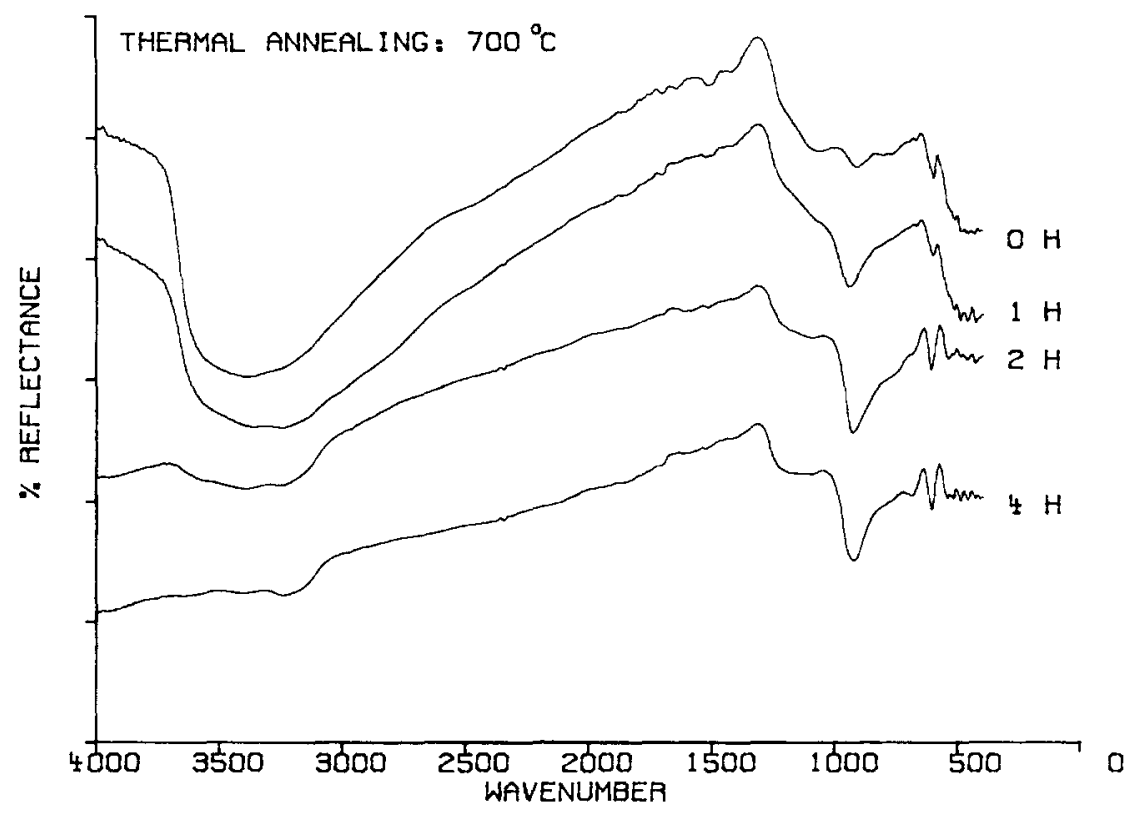

Fig. 5. FTIR absorbance spectra of alumina films annealed at $700^{\circ} \mathrm{C}$ for $0,1,2$ and $4 \mathrm{~h}$.

thin alumina films are generally related to the internal stress, consisting of thermal and intrinsic (growth) stress, according to:

$\sigma_{\text {internal }}=\sigma_{\text {intrinsic }}+\sigma_{\text {thermal }}$

It was found previously [16] that thin alumina films deposited by MOCVD suffer from high intrinsic stresses. SEM analyses indicated that cracking and delamination of the alumina films, after having passed a critical thickness, took place during the deposition and not during the cooling period. Owing to this high intrinsic stress the alumina films bend concavely upward (see Fig. 7(a)), caused by a high intrinsic tensile stress in the outer surface of the film. Similar observations were found for vapour deposited tantalum [22] and chromium films [23]. Calculation revealed that the thermally 


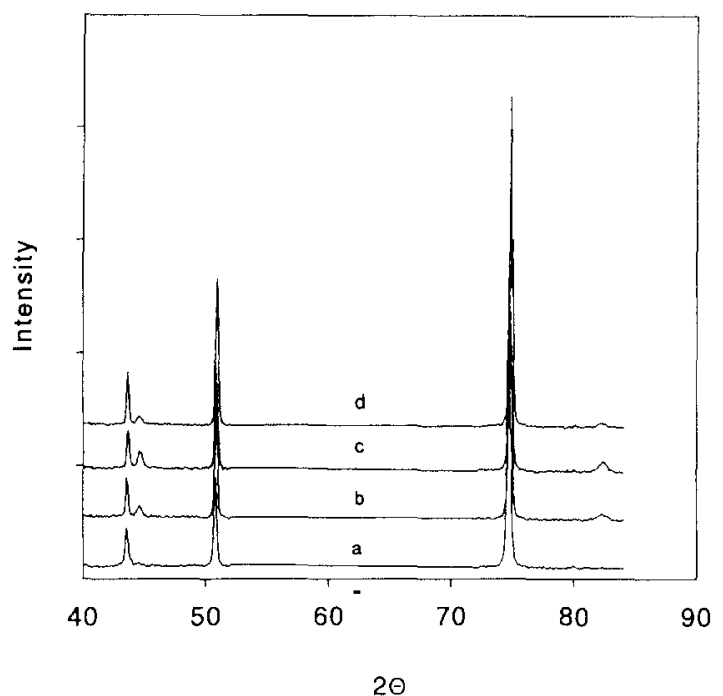

Fig. 6. XRD patterns of alumina films annealed at $700^{\circ} \mathrm{C}$ for (a) $0 \mathrm{~h}$, (b) $1 \mathrm{~h}$, (c) $2 \mathrm{~h}$ and (d) $4 \mathrm{~h}$

induced part of the internal stress is almost negligible [16].

A model for the generation of internal stress during the deposition process or thermal annealing process is illustrated in Fig. 8 [13]. If the film is under residual tensile stress, the film and also the underlying substrate will bend concavely, or, if under residual compressive stress, convexly. This form of the delaminated film after the post deposition thermal treatment (bending convexly) can be explained by an internal compressive stress which is concentrated at the outer part of the alumina film. If only the thermal stress in the alumina film on AISI 304 is considered, the stress can be calculated by the simplified equation:

$\sigma_{\text {thermal }}=E_{\mathrm{f}} \times \Delta T \times \Delta \alpha$

where $E_{\mathrm{f}}$ is the Young's modulus of the film, $\Delta T$ is the difference between deposition and actual temperature and $\Delta \alpha$ is the difference between thermal expansion coefficients.

Since the annealed alumina films on polished AISI 304 bend convexly (after delamination), it is suggested that the major part of the stress can be considered to be the thermal stress (residual compressive stress). Hence, the films without thermal annealing bend concavely as a result of high residual tensile stress. This means that after long annealing periods at high temperatures, the relaxation of the intrinsic stress is almost complete. For films with thicknesses below the critical value, the stress is determined by the sum of the intrinsic and thermal induced part. During the cooling period the alumina films form cracks. After annealing, almost no cracks were found. This can be explained by the fact that the

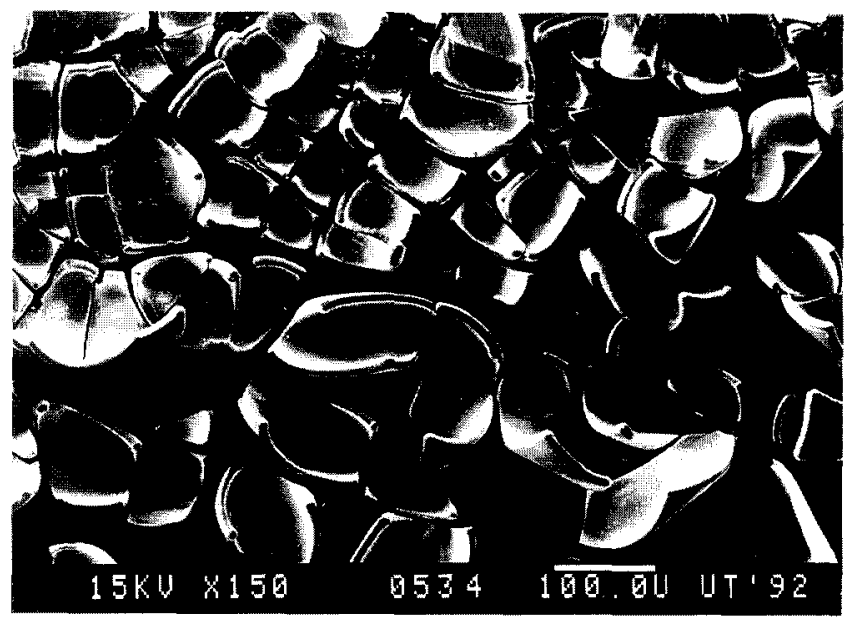

(a)

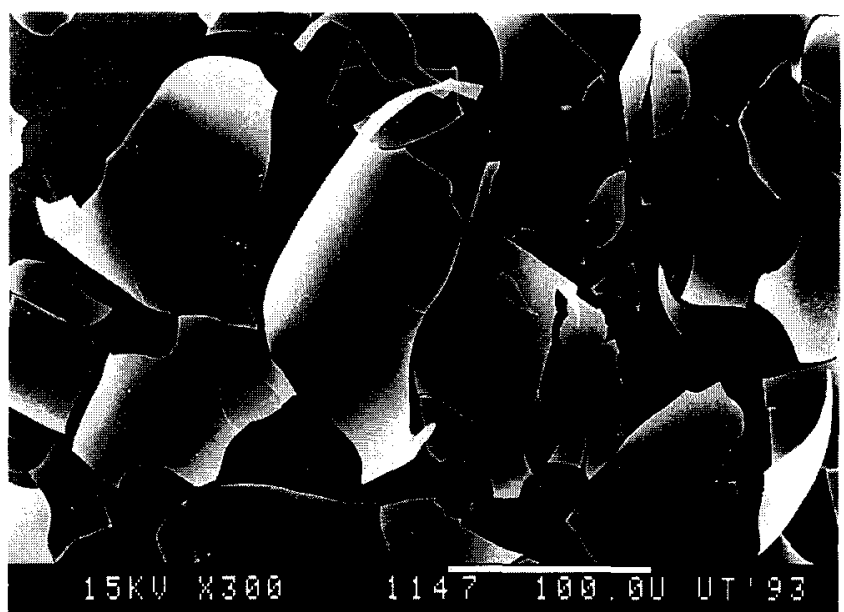

(b)

Fig. 7. Delaminated alumina film (a) during the deposition process the film bends concavely upward and (b) after thermal annealing for $4 \mathrm{~h}$ at $700^{\circ} \mathrm{C}$.
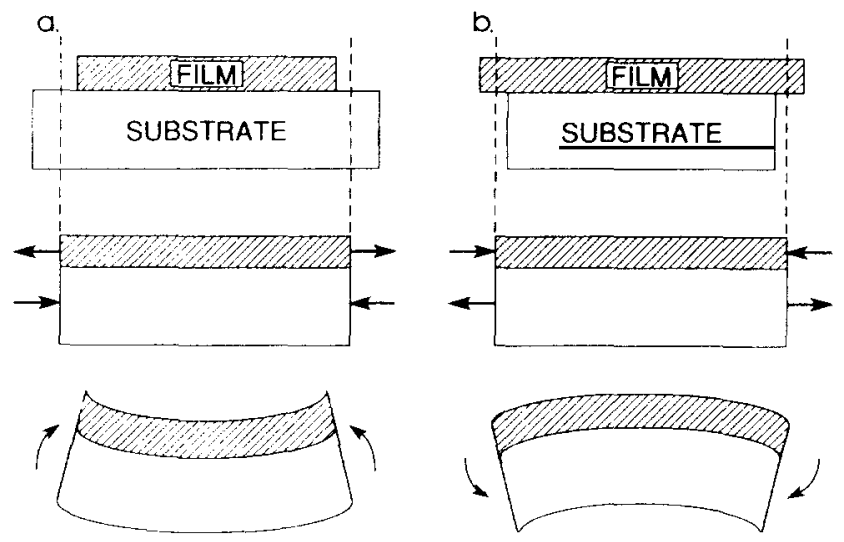

FILM UNDER RESIDUAL TENSILE STRESS

FILM UNDER RESIDUAL COMPRESSIVE STRESS

Fig. 8. A model for the generation of internal stress: (a) residual tensile stress in the film; (b) residual compressive stress in the film [10]. 
total internal stress of the oxide film is now determined only by the thermal stress.

A model of stress relaxation as a function of time and temperature has been developed by Desu [24]. Also the effect of deposition and annealing temperature on the film stress and the peak positions of the characteristic bending and stretching frequencies, obtained from FTIR spectra of the $\mathrm{SiO}_{2}$ films, was discussed by Desu [24,25]. For the alumina films it was found that the deposition temperature affects the peak position of the $\mathrm{Al}-\mathrm{O}$ band [15]. From the FTIR spectra obtained it was found that the maximum of the characteristic $\mathrm{Al}-\mathrm{O}$ peak, after the different post-deposition thermal treatment procedures, shifts towards a constant value around $928 \mathrm{~cm}^{-1}$. This probably means that no large difference in the internal stress is now present. If the high intrinsic stress is significantly reduced, the thermal stress now dominates the internal stress. The alumina films delaminated from the polished AISI 304 only at $700^{\circ} \mathrm{C}$ and $800^{\circ} \mathrm{C}$ - this may be explained by the higher thermal stress, caused by the larger difference between anneal and final temperature.

It is known that the alumina films on polished AISI 304 delaminate at $700^{\circ} \mathrm{C}$, but still show adhesion at temperatures of $600^{\circ} \mathrm{C}$. From eqn. (3) it can be calculated that the cohesive strength lies between $4.6 \times 10^{8}$ and $5.3 \times 10^{8} \mathrm{~N} \mathrm{~m}^{-2}$

The chemical composition of the annealed alumina films was investigated by AES and FTIR measurements. The steady state Auger spectra (survey scan) revealed aluminium, oxygen and also small amounts of carbon. However after one or more sputtering cycles carbon was no longer found, which might be explained by the adsorption of carbon containing compounds, such as carbon dioxide and hydrocarbons, on the outside of the alumina layer. This corresponds well with previous results [15]. From the AES depth profiles of the (low temperature and short period) annealed specimens it was clear that the concentration profiles of the aluminium, oxygen and the alloy elements (iron, chromium and nickel) are equal to those of the specimens without annealing. At longer annealing periods and/or higher annealing temperatures the interface oxide/alloy becomes less sharp, especially the chromium profile. The chromium penetrates more into the alumina films after longer annealing periods and higher temperatures. The nickel and iron profiles seem to be unaffected by the thermal treatment. Morssinkhof [9] reported that this behaviour can be explained by the structure of $\gamma$-alumina and the expected complete miscibility of $\mathrm{Cr}_{2} \mathrm{O}_{3}$ and $\mathrm{Al}_{2} \mathrm{O}_{3}$ with a substitution of $\mathrm{Al}$ by $\mathrm{Cr}$ in the oxide. This means that the interface structure changed significantly after severe post-deposition heat treatments and probably affects, for example, the cohesive strength and refractive index. Because of this interfacial composition profile change, no refractive index could be determined. The effect of the underlying diffusion zone on the total value of index of refraction was not known and could not be eleminated in a simple way. Therefore no values of the refractive index are shown.

The chemical structure of the films was analyzed by FTIR and XRD. To identify groups such as $\mathrm{OH}$ in the alumina film, which could not be detected by EDX or AES, FTIR was used. The presence of $\mathrm{OH}$-groups was suggested [15] by the incorporation of $\mathrm{AlO}(\mathrm{OH})$ or $\mathrm{H}_{2} \mathrm{O}$ in the alumina film, which is probably due to an incomplete conversion of the pyrolytic decomposition of the precursor. After $4 \mathrm{~h}$ of annealing the $\mathrm{OH}$-peak had almost disappeared which implies that the hydrogen impurity is significantly reduced. As a result of the high temperatures of the annealing process, reaction (1) will proceed to form $\gamma$-alumina. The next step is the dehydration of the formed alumina, as shown in Fig. 9 [26], which shows various tranformation sequences for the formation of alumina. It was also clear that the characteristic $\mathrm{Al}-\mathrm{O}$ IR absorption band changed in shape. For the unannealed specimens (deposition temperature, $330^{\circ} \mathrm{C}$ ), the Al-O peak is smooth and broad, but becomes sharper with longer periods and higher temperatures of the anneal process. Morssinkhof [9] related this effect to a decrease in the amount of $\mathrm{OH}$, which also has a peak at $1050 \mathrm{~cm}^{-1}$. Kang and Chun [5] related the effect to the fact that in general the IR spectra of amorphous materials are smooth and broad, while those of crystalline materials are relatively sharp. This corresponds well with the results obtained from the XRD measurements. The XRD analysis shows that after the annealing process of the alumina films, small peaks were observed, indicative of the presence of $\gamma$-alumina. XRD analysis did not reveal any characteristic alumina peaks of the unannealed specimens because the degree of crystallinity was too small to be detected [15]. Temple and Reisman [7] performed post-deposition thermal treatments of $100-180 \mathrm{~nm}$ thick alumina films on silicon substrates for $15 \mathrm{~min}$ at $1000^{\circ} \mathrm{C}$ and $60 \mathrm{~min}$ at $800^{\circ} \mathrm{C}$. No X-ray diffraction spectra were found for any phases in the alumina film, which is probably because these films were too thin for XRD measurements. The formation of $\gamma$-alumina after the post-deposition thermal treatment corresponds well with the results by Aboaf [27], Morssinkhof [9] and Boldyrev et al. [17]. For example, Aboaf [27] found that the heat treatment of the alumina films in argon at $600^{\circ} \mathrm{C}$ for $1 \mathrm{~h}$ only resulted in diffuse electron diffraction patterns. After $1 \mathrm{~h}$ at $800^{\circ} \mathrm{C}$, the $\gamma$ alumina phase was also detected. After $3 \mathrm{~h}$ at $800^{\circ} \mathrm{C}$, the amorphous phase had completely disappeared.

Summarizing, the thermal annealing procedures described in this paper probably allow stress relaxation in the MOCVD alumina films. The porosity of the films was not affected by this post-deposition thermal treat- 


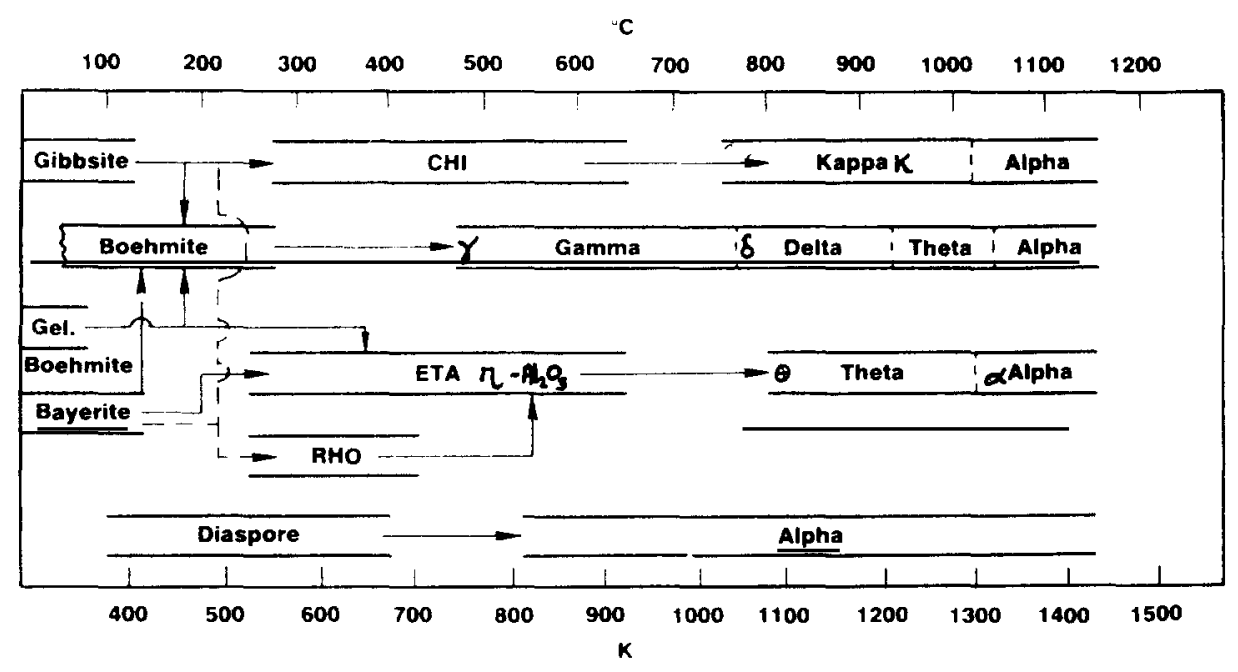

Fig. 9. Transformation sequence for the formation of alumina [26].

ment, but the cracks in the film disappeared almost completely. As a result of the thermal treatment after the deposition process, the hydrogen impurity also disappeared and the $\mathrm{AlO}(\mathrm{OH})$ (boehmite) was almost completely converted to dehydrated $\gamma-\mathrm{Al}_{2} \mathrm{O}_{3}$.

\section{Conclusions}

The pyrolytic decomposition of ATSB carried out at atmospheric pressure in the low temperature range $290-420^{\circ} \mathrm{C}$ in nitrogen, resulted in the deposition of thin alumina films, containing pores and cracks.

From the corrosion experiments it was observed that the cracks in the alumina films completely disappeared during the post-deposition heat treatment. This is explained by a reduction of the internal stress. The porosity of the alumina films was not affected by this heat treatment.

From the FTIR spectra it was shown that the $\mathrm{OH}$-groups disappeared after $4 \mathrm{~h}$ of thermal annealing at 600,700 or $800^{\circ} \mathrm{C}$. During the annealing the oxide/alloy interface changes as a result of diffusion of chromium into the alumina matrix, as shown by the AES depth profiles. XRD measurements showed that after the thermal annealing processes the alumina films were converted to $\gamma$-alumina.

\section{Acknowledgments}

This research was supported by the Innovative Research Program on Technical Ceramics (IOP-TK) with financial aid from the Dutch Ministry of Economic Affairs. Thanks are due to G.J.M. Weierink for the FTIR measurements, A.H.J. van den Berg (CMO) for the AES experiments, J. Boeijsma for the XRD measurements, K. Eijkel (MESA) for the ellipsometry measurements and to T. Kachlicki (CMO) for the TEM analysis, all at the University of Twente.

\section{References}

1 V.F. Korzo, Zh. Prikl. Khim., 49 (1) (1975) 74.

2 C. Dhanavantri and R.N. Karekar, Thin Solid Films, 127 (1985) 85.

3 R.A. Jacobson, Phys. Thin Films, 8 (1975) 51.

4 R.S. Ehle, B.J. Baliga and W. Katz, J. Electron. Mater., 12 (3) (1983) 587.

5 C.J. Kang and J.S. Chun, Thin Solid Films, 189 (1990) 173

6 J.F. Verweij, Insulating films on semiconductors (1979), Inst. Phys. Conf. Ser., $50(1980) 62$

7 D. Temple and A. Reisman, J. Electron. Mater., 19 (9) (1990) 995.

8 R.A. Abbott and T.I. Kamins, Solid State Electron., 13 (1970) 565.

9 R.W.J. Morssinkhof, The deposition of alumina films on steels by MOCVD, Ph.D. Thesis, University of Twente, Enschede, 1991.

10 K.P. Pande, V.K.R. Nair and D. Gutierrez, J. Appl. Phys. 54 (9) (1983) 5436 .

11 J. Saraie, J. Kwon and Y. Yodogawa, J. Electrochem. Soc., 132 (4) (1985) 890.

12 F. Ramos and M.T. Vieira, Mater. Manuf. Process. 7 (2)(1992) 251

13 M. Ohring. The Materials Science of Thin Films, Academic Press, Inc. Harcourt Brace Jovanovich, San Diego, CA, 1992.

14 V.A.C. Haanappel, H.D. van Corbach, T. Fransen and P.J. Gellings, Corrosion resistant coatings produced by metal organic vapour deposition using aluminium-tri-sec-butoxide, Thin Solid Films, in press.

15 V.A.C. Haanappel, H.D. van Corbach, T. Fransen and P.J. Gellings, Properties of alumina films prepared by atmospheric pressure metal organic chemical vapour deposition, Surf. Coat. Technol., 63 (1994) 145.

16 V.A.C. Haanappel, H.D. van Corbach, T. Fransen and P.J. Gellings, Cracking and delamination of metal organic vapour deposited alumina and silica films, Mater. Sci. Eng., A167 (1993) 179.

17 V.F. Boldyrev, V.M. Koleshko, B.S. Reznikov. I.V. Nekaryukin, L.D. Buiko and K.D. Yashin, Neorg. Mater., 12 (1976) 2181. 
18 H.C. Stumpf, A.S. Russell, J.W. Newsome and C.M. Tucker, Ind. Eng. Chem., 42 (1950) 1398.

19 R. Goton, Ph.D. Thesis, No. 146, University of Lyon, 1955.

20 J. Bugosh, R.L. Brown, J.R. McWhorther, G.W. Sears and R.J. Sippel, Ind. Eng. Chem., Chem. Prod. Res. Dev., 1(3)(1962) 157.

21 H. Saalfeld, Neues. Jahrb. Miner. Abh., 95 (1960) 1.

22 R.M. Fisher, J.Z. Duan and J.B. Liu, in M.F. Doerner, W.C. Oliver, G.M. Pharr and F.R. Brotzen (eds.), Mater. Res. Soc. Symp. Proc. 188, Materials Research Society, Pittsburgh, PA, 1990, p. 257.

23 R.M. Fisher, J.Z. Duan and A.G. Fox, in J.C. Bravman, W.D. Nix,
D.M. Barnett and D.A. Smith (eds.), Mater. Res. Soc. Symp. Proc. 130, Materials Research Society, Pittsburgh, PA, 1989, p. 249.

24 S.B. Desu, Jpn. J. Appl. Phys., 30 (12B) (1991) 2123.

25 S.B. Desu, in T.M. Besmann and B.M. Gallois (eds.), Mater. Res. Soc. Symp. Proc. 168, Materials Research Society, Pittsburgh, PA, 1990, p. 221.

26 K. Wefers and C. Misra, Oxides and hydroxides of alumina, Alcoa Technical Paper No. 19 (revised), Alcoa Research Laboratories, East St. Louis, IL, 1987.

27 J.A. Aboaf, J. Electrochem. Soc., 114 (1967) 949. 